\title{
Exploration on the New Teaching Mode of College Chinese
}

\author{
Dang Zijun, Yu Hongyan \\ Weinan Normal University \\ Weinan City, Shaanxi Province, 710049
}

\begin{abstract}
As an important course for higher education, College Chinese has a far-reaching significance on broadening students' horizon, improving students' humanistic quality, and inheriting Chinese civilization spirits. However, it is regrettable that the current status of College Chinese teaching is worrying and the problems in College Chinese teaching are becoming more and more prominent. On the basis of fully understanding the current status of College Chinese courses, this article has explored the new methods and modes of Chinese teaching through the combination of teaching practice and theoretical research.
\end{abstract}

Keywords-Driving teaching with learning; College Chinese; Quality-oriented education

\section{INTRODUCTION}

It has been mentioned in the National Middle and Longterm Education Reform and Development Outline Issued and Printed by CPC Central Committee State Council (2010-2020) that: "it is requested to pay attention to the combination of learning and thinking, advocate students' interests and hobbies, and build a good environment for independent thinking, and free exploration." [1] In the new round of reform, it emphasizes on updating the concept of talent cultivation, i.e., building the talent cultivation concept of teaching students in accordance of their aptitude, encouraging individualized development, and cultivating diversified talents. Besides, it advocates innovative talent cultivation mode, i.e., on the precondition of following education rules and talent growth rules, deepen teaching reform, explore characteristic teaching method and various cultivation modes, and form the situation of constant emergence of various talents and innovative talents. Thus, as the local higher education normal universities, with respect to the cultivation of college students' Chinese quality, it is requested to pay attention to mobilizing students' learning enthusiasm and imitative as per the Chinese knowledge and self-cultivation of students, implement heuristic guidance and help students study, develop the advantage potential of each student, lay a foundation for establishing and developing students' quality, and this is meaningful for creating social composite talents with innovative spirits and practical capacity. Thus, I will elaborate from the following aspects considering the valid execution issues for the mode of "driving teaching with learning" in the teaching of College Chinese:

\section{TRANSFORMATION OF EDUCATION CONCEPT}

Most teachers think that, teaching is the main classroom teaching mode focused on the course teaching of teachers, and it is a kind of learning activity for which students will passively accept knowledge through the knowledge teaching of teachers in the classroom. This is a traditional teaching mode, and also a common teaching method for students to conduct basic knowledge reserve learning during primary school. However, under the big background of education reform put forward by the state, as the higher education university focused on cultivating students' basic capacity, this traditional teaching method is obviously not applicable anymore; when being compared with it, "people-oriented" education concept and the teaching mode of "driving teaching with learning" have broken through traditional rules, and gradually recognized by quality education advocators.

The traditional teaching mode is what we often said as fivesection teaching, including organizational learning, review checking, new course teaching, learning reinforcement, and homework assignment; under such teaching mode, it is oriented to what is taught by the teacher, emphasizes on knowledge teaching, and from the start to the end of the class, the teacher will merely repeat what the book says through the mode of cramming education, subjectively hold that students understand them, and then adopt the mode of arranging homework to check and evaluate the learning effect of students As a student, it is more like watching a play, and listening to stories, and they are always under repressed and passive status, and cannot timely give feedback information, or interact and communicate with teachers, and lack in learning enthusiasm, which will influence the classroom teaching quality. Finally, students will practice and think hard in the classroom, and easily spend a day, and if they don't know how to do the homework, they will be under huge pressure, and cause vicious circle and school-weary emotion. In a word, the original classroom teaching structure cannot adapt to the requirements of quality education, and cannot efficiently implement course objective in place, so reform is necessary.

Under "people-oriented" education concept, the teaching mode of "driving teaching with learning" will be generated. The so-called "people-oriented" education mode is actually a new type of education concept, and it not only requires us to break through the traditional teaching thinking mode, and design new teaching mode, but also requires us to take 
individualized development as the orientation on the basis of the actual conditions and demand of individuals, fully mobilize students' subjective initiative, and stimulate students' potential. [2] The so-called teaching mode of "driving teaching with learning" refers to taking the autonomous learning of students as the main line running through the entire teaching process, and students can make the best of the both worlds and help each other through classroom interaction, discussion and other modes, so as to improve self-learning capacity, and as for teachers, they are requested to give innovative and specific teaching explanation. Drive teachers to teach through the learning of students, and let teaching more efficient and specific. Besides, the teaching mode of "driving teaching with learning" can also promote the formation of the relationship of good teachers and helpful friends, promote the formation of harmonious, democratic and easy classroom climate, and realize a solid foundation for efficient classroom.

\section{DISTINGUISH ROLES AND RETURN AUTONOMOUS RIGHT OF LEARNING TO STUDENTS}

In the entire teaching activity of "driving teaching with learning", it is requested to fully recognize the students' dominant role, and students are not only the education object, but also the subject of self-education and development, and the pattern of manifestation mainly involves the students' independence, creativity and consciousness [2]. Independence is the internal impetus for the self-development of students, and it is the capacity of students to independently find and solve problems. Creativity is the highest pattern of manifestation for students' learning subject function, and it can promote students to open up thoughts, and then image, process and convert on the basis of existing data, and meanwhile, use brand new mode to cognize the new field, and then drive teachers' teaching activity. Consciousnesses refers to students' active and positive participation in the teaching activity, converting passiveness into initiative, realizing external requirements and selfdevelopment, regarding themselves as their own cultivation objective, and making learning into their own activities. Therefore, creativity is the main factor of "driving teaching with learning”.

For instance, in the teaching of "Xiang Yu Basic Annals" in Historical Records, A drama called Sima Qian was released at our city, Mr. Feng Yuanzheng gave a lecture at our school upon invitation. I mobilized all students to listen to the lecture, and let them feel the understanding and cognition of famous celebrities on the historical character, and let them have a comprehensive understanding on Historical Records and Sima Qian. After that, I utilized multi-media technology and adopted the mode of asking questions to drive the whole class to jointly read "Xiang Yu Basic Annals". Through this way, students can not only learn the contents of "Xiang Yu Basic Annals", but also have a primary cognition on Historical Records and Sima Qian. By virtue of model effect, I completed the teaching task of this part, and also stimulated students' interests in autonomous and spontaneous leaning, and the research of Historical Records.

\section{Cultivate STUDENTS' LEARNING INTEREST AND MOBILIZE STUDENTS' ENTHUSIASM AND INITIATIVE}

Interest is the internal impetus for the learning of students. Only when there is interest can we discuss how to learn better, and find out good learning method and skills. The learning interest is mainly expressed as a positive and pleasant learning trend [3]. For the interested disciplines, they can autonomously and spontaneously conduct research with a pleasant emotion. Due to autonomous and spontaneous research, good learning effect can be generally obtained. Such effect can constantly improve the confidence of students in learning, make them believe that they can learn this discipline well and then become willing to spend more time in learning. Promote their interested disciplines into their own advantages. Just like what Tolstoy said: "what successful teaching requires is not constraint, but the motivation of students' interests" thus it can be seen that, interests exert a directing effect on the success of teaching, and whether the students' interests can be kept and develop is largely decided by whether the teaching effect is good or not [4].

For instance, in the teaching of Tang Poetry courses, I won't blindly introduce the author, writing background, poem writing characteristics and other knowledge, but adopt task teaching mode as per the requirements of talent cultivation scheme in our school. Firstly, I divided the students in the class into several groups, which were led by group leaders, and participated by each group member, and they would select one poem for reading. Secondly, before students showed their group work, I would firstly play some videos to guide students to understand the reading contents and applicable mode in combination with the relevant contents about the "Chinese Classic Reading" activities in our school, and in the preparation period of students, I would give some constructive opinions to students for reference. Next, in the link of exhibition for students, firstly, each group conducted poem reading, and after all groups completed, I evaluated as per the classification of poems read by each group, gave praises and affirmation on the work of students. After that, I played the fragments of some relevant works read by famous celebrities, let the students feel their disadvantages in emotional expression during work reading, and aroused their interests in classic reading. Finally, returned to the textbook, summarized the knowledge points of this chapter therein, and conducted the horizontal expansion of knowledge scope on this basis, and let students develop a systematic cognition on the evolution of entire Tang poetry, which can not only guide and arouse students' curiosity and intellectual curiosity for Chinese classics, but also mobilize an easy and alive classroom climate, improve the teaching quality of teachers and the learning efficiency of students, and lay a solid foundation for the practical research of efficient classroom. 


\section{ADVOCATE READING, Guide STUDENTS to PARTICIPATE, AND Motivate STUDENTS' Potential}

Sukhomlinskii said that: "in the most literal terms, reading is not only a boat of thinking we used for sailing, but also a swelled sail, and the wind for sailing forward; without reading, there is no sail, or wind. Reading is like independently sailing in the sea of knowledge". It can be seen that reading plays a crucial role in the learning of Chinese knowledge [5].

Speaking of reading, what should we read, and how to read? This is a problem that worth considering for Chinese teachers. Some people hold that reading is aimed to expand extracurricular reading quantity, and the more you read, the broader your horizon will be, and the knowledge scope will be increased accordingly. But I think that, the reading object can be both the extracurricular textbook, and the in-class textbook, which should be mainly decided by our teaching objective. Meanwhile, reading activity is a kind of complicated thinking process, and the process for readers to select, and process the materials. If students lack in systematic guidance in reading, teachers cannot obtain the expected teaching effect. Thus, reading teaching method has certain application range, and it is mainly applicable to some classic chapters with literary appreciation value.

For instance, in the teaching of $\mathrm{Ci}$ and $\mathrm{Qu}$ written by $\mathrm{Li}$ Qingzhao, the representative female $\mathrm{Ci}$ poet of graceful and restrained poetic genre, teachers shouldn't urgently make explanation, but give the initiative to students. Firstly, they shall let students independently prepare one $\mathrm{Ci}$ or $\mathrm{Qu}$ written by Li Qingzhao for reading after class as per the form of group, and discuss about their feelings after reading. Through reading, think about the intention of the author, the basic meaning of words, the pronunciation, font, and statement characteristics. Secondly, let students read in class taking group as the unit, and discuss about their feelings, while the members of other groups can make supplementation. Through this mode, it can not only mobilize students' enthusiasm, and stimulate the students' potential, but also receive the feedback about the students' Chinese knowledge mastering degree, and let teachers have certain rules to follow during teaching design, and teach students in accordance of their aptitude. Finally, teachers can apply questioning method to lead students to conduct systematic summary and relevant knowledge supplementary about all kinds of $\mathrm{Ci}$ and $\mathrm{Qu}$, such as the time for the $\mathrm{Ci}$ poet to write this $\mathrm{Ci}$, the language characteristics, and the mental state of $\mathrm{Ci}$ people; and then in combination with the life story of $\mathrm{Ci}$ poet, analyze the changing characteristics of $\mathrm{Ci}$ and $\mathrm{Qu}$ written by $\mathrm{Ci}$ poet during different periods. This is the reading process, and the key is to "read", i.e., reading and feeling about the beauty of the article writing style. Under the lead of teachers, students can experience Chinese classic beauty, and then improve aesthetic taste.

In the entire teaching activity, students can obtain knowledge, find problems and solve them through autonomous exploration, so as to motivate their interests in Chinese classic literature, and develop their advantage potential. Meanwhile, teachers will encourage students to independently conduct indepth research about their interested knowledge points as per the respective characteristics of students, exert the function of "driving teaching with leaning", and build individualized talents.

American Educator Bacon said that: "studies serve for delight, for ornament, and for ability." It can be seen that, reading can increase students' personal taste, reinforce students' moral cultivation, and promote harmonious development of the society, with an ignorable significance. Teachers shall pay attention to guiding students to widely read works with positive, healthy and progressive contents, and being be unconsciously influenced, the thoughts of students can resonate with the thoughts of the author, and then be gradually edified by the thoughts of the author, and form noble view of life and value concept.

\section{TAKE STUDENT AS LEADER IN THE ClASSROOM AND BuILD AN EASY AND PlEASANT CHINESE ClassROOM ATMOSPHERE}

The key factors deciding whether the teaching is successful or not is to implement students-oriented and teacherssupplemented, encourage more, and create a good relationship between teachers and students and classroom climate.

Teachers can adopt task teaching mode, for instance, asking students to come to the state to give a speech, or adopt role playing teaching mode, to mobilize students' learning enthusiasm and initiative, and play the leading role of students. In the process, teachers can encourage students through smiling, nodding, affirmative eye contact and other body languages, so as to zoom in the spiritual distance between teachers and students, establish personality charm, and win the respect of students, and then let students accept instructions with an open mind, generate full learning passion and everlasting learning motivation, which is also the precondition for "driving teaching with learning".

For instance, in the study of Li Bai's Everlasting Regret, due to the long length of the poem, the rich contents, and strong storytelling characteristics, if it is taught step by step from introduction about the author to text analysis, and famous phrase appreciation, etc., students may generate boring and averse resistance feelings. Therefore, in the teaching of Everlasting Regret poems, I utilized the environment advantages - Weinana is located at the south of Shaanxi, and is close to the places where the stories happened, including Lintong Huaqing Pool, Maweiyi, and Xingqing Palace; besides, the song and dance drama of Everlasting Regret performed at Huaqing Pool. Through utilizing these resources, I successfully drew the interests of students, and then I seized time by the forelock, encouraged the whole class to arrange a small drama and participated in the New Year Party Performance. When arranging the drama, I can analyze, and study each sentence of the poem with my students, and only when the development vein of the entire poem can be clearly understood can we clearly understand the contents and emotions of each sentence, and then extract essence therein, and show it through the form of drama. Meanwhile, in order to arrange a drama, the actors should also comprehend the character, and master the accuracy for using each line to express thoughts and feelings. 


\section{SUMMARY}

To sum up, the party central committee and country taking General Secretary $\mathrm{Xi}$ Jinping as the center attach great importance to the inheritance and promotion of traditional culture, [6] so the exploration on the education mode of College Chinese taking the inheritance of traditional cultural spirits as the objective is very important and urgent. Meanwhile, the new challenges faced by College Chinese education require constant reform exploration. This requires teachers of College Chinese to conduct research exploration from the classroom teaching practice, specific teaching method and other perspectives, and realize the education objective of inheriting Chinese traditional culture through the teaching of College Chinese.

\section{ACKNOWLEDGMENT}

About the Author: Dang Zijun (January 1, 1985), female, born in Xi'an, Shaanxi, the Lecturer, and Master of Education for Weinan Normal University, and is mainly engaged in the exploration and practice of new concept and new method in classroom teaching as well as research on the relationship between the learners' thinking difference and the teaching method in the teaching of Chinese as a foreign language.

Fund Project: This article is the research achievement of Scientific Research Project of Humanities and Social Sciences
Category (Project No.: 16SKYB22) in Weinan Normal University, the education reform research project (Project No.: JG2016459) of Weinan Normal University, and the education science international cooperation research project (Project No.: 17GJHZ28) of Weinan Normal University.

\section{REFERENCES}

[1] National Middle and Long-term Education Reform and Development Outline Issued and Printed by CPC Central Committee State Council (2010-2020) [J]. People's Education, 2010 (17): 2-15.(In Chinese)

[2] Huang Yan. Research about the Classroom Teaching Practice of Driving Teaching with Learning in Primary School Mathematics [J]. Arts and Science Guidance (the Last Ten-day of a Month), 2013(05):31. (In Chinese)

[3] Chu Yongmei. Brief Discussion about the Application of Core Attainment of English Teaching in Lower Years of Primary School. Knowledge Library, [2016-07-28]. (In Chinese)

[4] Li Chaobo. Brief Discussion about Understanding Students in Teaching [J]. New Curriculum (Middle School), 2012 (12): 140-141. (In Chinese)

[5] Hou Jie. Brief Discussion about the Reading of Middle School Chinese [N]. Knowledge Journal, 2010-09-20 (A01). (In Chinese)

[6] Huang Zhicheng. How to Inherit Traditional Culture in the Teaching of College Chinese [J]. Journal of Chifeng University (Chinese Philosophy Social Science Version), 2015 (34): 194. (In Chinese) 